\title{
Handle with care
}

\section{Given that universities and companies have such different needs, is it appropriate for them to have partnerships, and if so, is some form of regulation required?}

The level of interaction and cooperation that it is healthy for universities to have with industry is a somewhat controversial point, and an especially relevant one for photonics research. The topic was discussed in detail at the recent fifth annual meeting of the STS forum ${ }^{1}$ in Kyoto, Japan, in October. Put simply, opinion tends to fall into two strongly opposing camps.

On the one side there are those who believe that universities should be dedicated to education and conducting fundamental, curiosity-driven research, and that this position should not be threatened or steered by commercial interests or pressure from industry. Fears are sometimes expressed that if industry-sponsored research is too dominant then universities run the danger of becoming nothing more than an outsourced company R\&D lab and the companies will 'buy' excessive control of a university's research directions.

Such opinions hit the headlines when the energy company British Petroleum (BP) announced plans in February 2007 to fund, by means of a $\$ 500$ million 10-year grant, a research centre called the "Energy Biosciences Institute" ${ }^{2}$ at the University of California, Berkeley, in the United States.

The deal has now gone ahead but is still highly controversial. At the time it provoked uproar at UC Berkeley, resulting in student demonstrations and a campaign to block the deal ${ }^{3}$ with cries of "We don't want the blood money," and "Stop the Trojan horse gift," regarding the perceived threats on the university's independence and reputation.

On the other side there are those who believe that close interaction between universities and industry is essential for giving a country a strong and thriving science and technology base, especially in developing nations. They comment that there are many benefits to gain from a close collaboration or partnership between the two parties. For example, they cite more rapid commercialization of technology, access to funding and equipment that the universities would not otherwise have, and the opportunity for companies to investigate high-risk or blue-sky research that they would not otherwise undertake.

Indeed, one of the strong messages to come from our interview with Gustav Kalbe, the head of the European Commission's Photonics

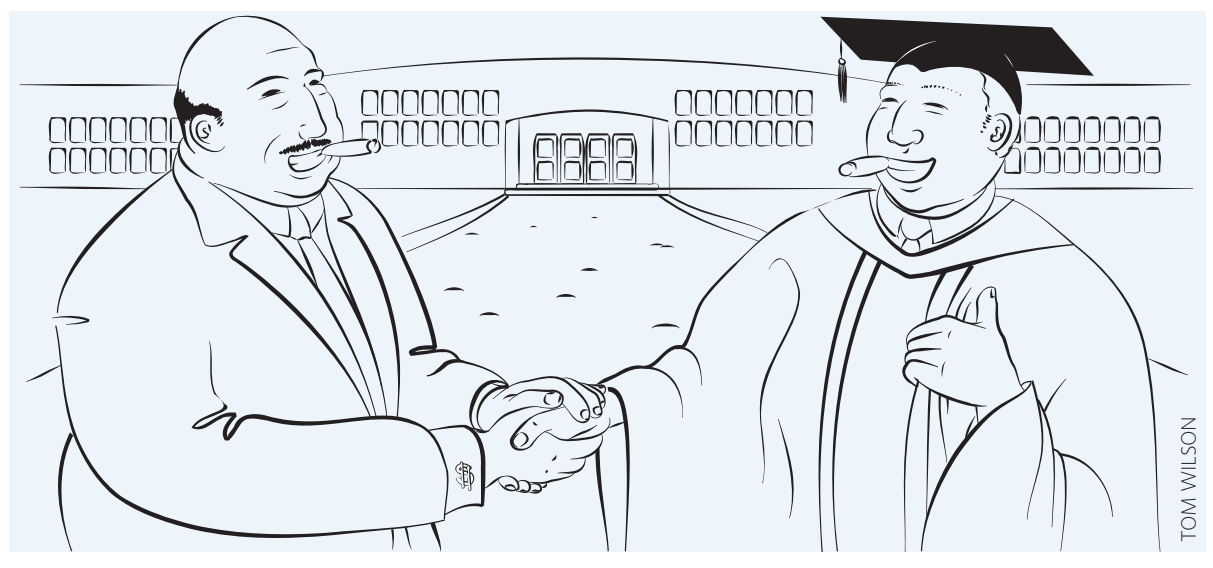

Unit, in January ${ }^{4}$ is that the Commission, through its 7th Framework Programme (FP7), is keen to foster and improve the relationship between small-to-medium enterprises (SMEs) and universities in Europe.

\section{"Partnerships between universities and industry need to be handled carefully"}

"We see the link between universities and SMEs as being vital for innovation," he stated in our January issue. "Considering the strong application and orientation of photonics, a project [within FP7] is more credible if it has an industrial or private company in the consortium."

Certainly, in photonics the level of interaction between industry and universities is already extremely active, given that so much of the research, even at a fundamental level, has such strong potential applications and opportunities for commercialization. Indeed, it is hard to find an optics group at a European university that does not already have some kind of strong connection to industry, through either a sponsored research programme or a cluster of spin-off or start-up companies.

Regardless of whether you feel that such collaborations are a threat to independence or a benefit to innovation, most would agree that before such partnerships are undertaken it is vital that important issues are discussed, such as how intellectual property and the publication of research findings will be handled. After all, each party needs to be satisfied that it will benefit.
And this perhaps is ultimately where the difficulty lies in making things work. At a fundamental level, universities and industry want different things and have different criteria for measuring success. Whereas a university is likely to be happy if the research results in a series of published papers, a company is more likely to want patents and a route towards commercialization. The problem is that there is often a conflict between these needs, especially in terms of how or whether results are disclosed.

The difficult task for governments and universities is to find the best model that somehow allows all the benefits of collaboration to flourish without jeopardizing some of the core values of a university or the attractiveness to companies.

The truth is that it is a difficult situation to handle, but we are certainly of the opinion that universities should not be pushed into a corner in terms of having targets for industry funding or being penalized for not having it. We also believe that it is important that universities continue to have independent funding that can be spent on research efforts with no obvious industrial applications. After all, we shouldn't forget that the laser itself has often been called an invention looking for an application, and such curiosity-driven research is vital for science. We welcome your comments on the matter.
References
1. www.stsforum.org
2. http://www.energybiosciencesinstitute.org
3. http://stopbp-berkeley.org
4. Gevaux, D. Nature Photon. 3, 2-3 (2009). 